\title{
Streitentscheidung und Normbildung durch den Zivilprozess
} Eine rechtsvergleichende Untersuchung zum deutschen, englischen und US-
amerikanischen Recht

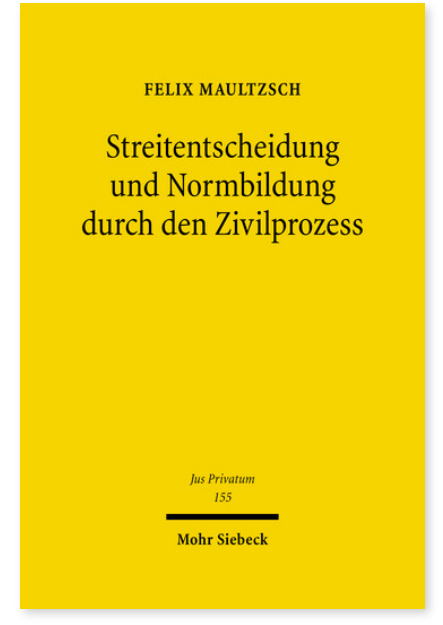

2010. XXV, 492 Seiten. JusPriv 155

ISBN 978-3-16-151232-2

DOI 10.1628/978-3-16-151232-2

eBook PDF 119,00€

ISBN 978-3-16-150538-6

Leinen $119,00 €$
Die richterliche Normbildung verkörpert einen immer bedeutsamer werdenden Aspekt der höchstrichterlichen Tätigkeit. Hiermit stellt sich zugleich die Frage, in welchem Verhältnis diese Normbildung zu der Entscheidung des jeweils anhängigen Rechtsstreits steht. Bildet der konkrete Fall den wesentlichen Entscheidungs- und Erkenntnisgegenstand, aus dem zugleich allgemeinere Rückschlüsse gezogen werden, oder bildet er einen bloßen Anlass für eine abstrakt orientierte Normbildung? Felix Maultzsch geht dieser Frage in einer rechtsvergleichenden Untersuchung zum deutschen, englischen und USamerikanischen Recht nach, die sich an dem prozessual-institutionellen Rahmen der richterlichen Tätigkeit orientiert. Er untersucht das Verhältnis zwischen Streitentscheidung und Normbildung aus entwicklungsgeschichtlicher und

rechtstheoretischer Perspektive und behandelt zudem konkrete prozessuale Anwendungsbeispiele. Hierbei kann für die höchstrichterliche Ebene die Grundtendenz beobachtet werden, dass die Normbildung einen immer stärkeren Eigenwert erlangt und sich von der Streitentscheidung gleichsam loslöst. Der Autor plädiert demgegenüber für eine Rückbesinnung auf das klassische Modell, nach dem der jeweilige Fall das Zentrum der richterlichen Tätigkeit bildet und die Rechtsschöpfung leitet. Dieser Ansatz konzentriert sich auf die genuinen Stärken des Prozesses der richterlichen Entscheidungsfindung und ermöglicht somit auf lange Sicht auch eine nachhaltigere Normbildung.

Felix Maultzsch ist Inhaber des Lehrstuhls für Zivilrecht, Zivilprozessrecht, Internationales Privatrecht und Rechtsvergleichung an der Goethe-Universität Frankfurt am Main.

Jetzt bestellen:

https://mohrsiebeck.com/buch/streitentscheidung-und-normbildung-durch-den-zivilprozess-9783161512322?no_cache=1 order@mohrsiebeck.com

Telefon: $+49(0) 7071-923-17$

Telefax: $+49(0) 7071-51104$ 